\title{
RESEARCH NOTES
}

\section{THE INTRODUCTION OF PROJECT MANAGEMENT AND PROJECT THINKING AT SECONDARY SCHOOLS}

\begin{abstract}
Introduction
This is not the first time the authors of a project management curriculum are dealing with the question of when to start instilling the principles of this subject into the young generation. The current proposal has brought a team of authors under the guidance of Prof. Dr. Michael Gessler from the University of Bremen (ITB - Institut für Bildung und Technik). In cooperation with GPM (Deutsche Gesellschaft für Projektmanagment), some support materials which show school leaders and teachers how to successfully teach the subject at secondary schools have been released.

This idea has also become the stimulus for a European project, in cooperation with six Central European schools (in Germany, Switzerland, Slovakia, Poland, and Turkey). In the Czech Republic, the Faculty of Business Administration at the University of Economics in Prague has signed up to participate in the project (2012-2013) under the guidance of Prof. Ing. Ivan Nový, CSc. The faculty's team, composed of academics and individuals from the private sector, issued - in cooperation with an expert team - original teaching material in the project workshops; they also submitted a vocational assessment. The project was even especially applied in two Czech secondary schools, which brought specific outputs and suggestions for next steps (Business Academy in Kroměřǐz and the SKODA AUTO Academy in Mladá Boleslav).
\end{abstract}

\section{What is New About the Idea?}

The subject of project management we know from the professional faculties of applied sciences and economics. Till now, however, this remarkable scope has not penetrated into the curriculum of secondary and high schools. Therefore project management has not yet been evaluated as a separate subject in the curricula of high schools. On the contrary, we have seen this subject be a pedagogical consideration of German and Swiss high schools for many years. Therefore they also consider project management for other European schools as an unrealized potential.

The justification of the determination is, on the one hand, the fact that students are able to learn this subject in an appropriate form far earlier than before entering university; on the other hand, now at the entrance to college or professional sector, they may be ready to deal with the basics of project thinking and project management. Specifically, the model was designed for the higher secondary classes or vocational schools with 30 teaching hours per semester. The main content of the subject should be an introduction and a comprehensive active teaching style, which takes place in the form of the selected project beyond the individual subjects and involving compulsory, optional and generally educational subjects.

\section{What do Thinking and Project Management do for Students?}

Project management is a working taxonomy introduced in professional practice. The aim of this proposal for students is "learning by doing". The emphasis of teaching relies on the active participation of students, particularly in planning, decision-making processes and systematic work in teams. Certainly, there is no place for passive submitting of knowledge by students. The teacher is the coordinator and supporter in methods and approaches for dealing with the proposed project, which the students solve themselves. Thanks to the fact that in the practical teaching of project management we meet multiple disciplines, we have to be prepared for a multidisciplinary approach for our teaching; this is necessary in order to find solutions for real projects. The multidisciplinary approach relates to the overall efficiency of the students and increases their practical goal orientation. In addition to working with students, the teacher has to build their feelings of responsibility, because they do not work on a project only for themselves, but also as a part 
of the team; this also improves the analytical, communication and cooperation capabilities of the students. The project management program in secondary schools aims to make students meet with a specific solution of project tasks while they are still in high school, to gain a better understanding of the real world, to know how to benefit from the methodological and social competences, which go beyond the standard framework of disciplines. The advantage of this training includes the ability to learn in a structured manner, to act as a team, to think systematically and learn how to establish priorities, problem solving, discussion, evaluation, and time management.

\section{Why Introduce Project Management into Vocational Schools?}

The main reasons to introduce project management into vocational schools include being active in innovative teaching methods in order to have better quality education in the schools as well as help students be better prepared to enter the professional sphere. Many important developmental processes today, companies and other institutions are organized in the form of projects. This systematic working position is, at present, more and more demanded and is becoming a standard need of companies for employees. If it weren't for the elements of project management, many organizations would long ago have failed in their business practices. With the need for project and management thinking in companies must go hand in hand a change in the training philosophy of future employees. The ability to work on projects, be part of a team to solve problems collectively and provide high-quality and reliable performance represents a significant professional competence. Project management is also directly related to the development of resourceful thinking, creative activities, and a comprehensive understanding of tasks. Improving all of these skills in the context of project management provides a far stronger assurance that the professional schools will graduate really competent alumni with experience in team work and use of entrusted responsibility.

There are several other additional points of output which will result from this Central European cooperation; these include:

- Methodological guide relating to the evaluation process of students; it is a complex process far more concentrated on project management than on evaluation and testing of particular memorized information.
- The necessary training of teachers of secondary and vocational schools, who themselves must first learn how to work with the prepared materials during practical training and know how to properly use the techniques with students.

- One seminar regarding cultural background has also been prepared; it is a very important piece for project management. The subject assumes a high personal responsibility of the teacher as well as healthy project thinking based on personal values, belief in the creative and innovative abilities of students, on respect for diverse personalities and culture (e.g. in intercultural teams) and the way of thinking of the team members, the ability to predict future development and discipline to control thinking and acting as well as the appropriate pedagogical thinking and action leading students toward future objectives. All of the listed abilities and competences are also related to openness and critical approach, which of course is never a simple task.

- Familiarity with the existing rich experience of German and Swiss high schools, where the teaching of project management and project thinking have been running with great success for several years, and will be further developed.

- The application and use of the prepared documents for a specific Czech and Central European secondary school environment.

Summing up the entire course of the international project, we can say that the idea and its realization of a pilot project have found a positive response among the members of the Expert Commission, and between the teachers and the students in all member countries. These provide sufficient reasons for its continuation.

For more information visit http://projektmanagement. vse.cz.

Mgr. Dušan Kučera, MBA

International School of Business and Management Faculty of Business Administration University of Economics, Prague Nám. W. Churchilla, 4, 13067 Praha 3 dusan.kucera@vse.cz 